\title{
Well-resolved hypocenter distribution using the double-difference relocation method in the region of the 2007 Chuetsu-oki Earthquake
}

\author{
Yohei Yukutake, Tetsuya Takeda, and Kazushige Obara \\ National Research Institute for Earth Science and Disaster Prevention, Tennodai, 3-1, Tsukuba, Ibaraki 305-0006, Japan \\ (Received November 30, 2007; Revised March 18, 2008; Accepted March 24, 2008; Online published November 18, 2008)
}

\begin{abstract}
The 2007 Chuetsu-oki Earthquake $\left(M_{\mathrm{j}}=6.8\right)$ occurred in the eastern margin of the Japan Sea where high strain rates have been observed and many large earthquakes have occurred. The main shock was located near the Western Nagaoka Basin active fault system dipping in the westward direction. We estimated the wellresolved hypocenter location around the main shock rupture zone from the differential arrival times obtained by both manual picking and waveform cross-correlation analysis. From the relocated aftershock distributions, we successfully resolved the detailed fault structures activated by the main shock. The estimated fault model resolves four individual fault segments. The fault model suggests that the main shock predominantly ruptured the southeastward dipping fault planes. On the other hand, the aftershocks around the hypocenter of the main shock occurred on both the northwestward and southeastward dipping fault planes. Both fault planes around the hypocenter of the main shock may have been nearly coincidentally ruptured during the main shock.
\end{abstract}

Key words: The 2007 Chuetsu-oki earthquake, aftershocks, hypoDD, fault structure.

\section{Introduction}

The 2007 Chuetsu-oki Earthquake occurred at 10:13 AM $($ JST $=\mathrm{UT}+9 \mathrm{~h})$ on July 16, 2007 with a Japan Meteorological Agency (JMA) magnitude $\left(M_{\mathrm{j}}\right)$ of 6.8 (Fig. 1). The moment tensor solution of the main shock determined by a broadband waveform inversion of the National Research Institute for Earth Science and Disaster Prevention (NIED) F-net was a reverse fault type with the $P$-axis in the WNWESE direction (Matsumoto et al., 2007). The $P$-axis direction was consistent with the tectonic maximum compressive stress direction in and around the Mid Niigata area (Townend and Zoback, 2006). The largest aftershock $\left(M_{\mathrm{j}}=5.8\right)$ occurred near the hypocenter of the main shock $4.5 \mathrm{~h}$ after the main shock occurred. The aftershock activity was lower than that recorded for previous intraplate earthquakes such as the 1995 Hyogo-ken Nanbu Earthquake $\left(M_{\mathrm{j}}=7.3\right)$, 2000 Western Tottori Earthquake $\left(M_{\mathrm{j}}=7.3\right)$, and $2004 \mathrm{Mid}$ Niigata Earthquake $\left(M_{\mathrm{j}}=6.8\right)$ (JMA, 2007).

The 2007 Chuetsu-oki Earthquake occurred in the Niigata-Kobe Tectonic Zone where high strain rates have been observed from GPS data analyses (Sagiya et al., 2000). The source region of the main shock was also located in the eastern margin of the Japan Sea, which is a region of many active faults and folds comprising a series of anticline structures and reverse faults (Okamura et al., 1998). Many large earthquakes have occurred along this active fault zone, such as the 1828 Echigo-Sanjo Earthquake $(M=6.9), 1964 \mathrm{Ni}-$ igata Earthquake $\left(M_{\mathrm{j}}=7.5\right)$, and 2004 Mid Niigata Earthquake. The Western Nagaoka Basin active fault system has westward dipping faults (Research Group for Active Faults

Copyright (c) The Society of Geomagnetism and Earth, Planetary and Space Sciences (SGEPSS); The Seismological Society of Japan; The Volcanological Society of Japan; The Geodetic Society of Japan; The Japanese Society for Planetary Sciences; TERRAPUB. of Japan, 1991) and is located approximately $10 \mathrm{~km}$ southeast of the epicenter of the main shock (Fig. 1). From the aftershock distribution determined by the NIED Hi-net routine analysis, we could roughly discriminate a southeast dipping alignment. However, it was difficult to reveal the fine structure of the main shock from the routinely determined hypocenters.

The purposes of this paper are to clarify the fault geometry ruptured during the main shock and to discuss the relation between the faults of the main shock and the surrounding active faults. First, we determined the initial hypocentral locations by employing the one-dimensional velocity structure and station corrections derived from the aftershock data of the 2004 Mid Niigata Earthquake (Shibutani et al., 2005). Next, we relocated these hypocenter locations with the help of the double-difference relocation algorithm (hypoDD) (Waldhauser and Ellsworth, 2000) using the differential arrival time obtained by both manual picking and waveform cross-correlation analysis.

\section{Data and Method}

We used 50 permanent online stations operated by the NIED Hi-net, JMA, and Earthquake Research Institute of the University of Tokyo (ERI) (Fig. 1). We used the dates of 1,399 earthquakes that occurred in and around the source region in the period between January 1, 2004 and July 18, 2007. The magnitudes of these earthquakes were greater than or equal to 0.2 . We manually picked $P$ - and $S$-arrival times, $P$ polarities, and the maximum amplitude.

\subsection{Initial hypocenter location}

The initial hypocentral locations of the earthquakes used for the hypoDD relocation were determined by applying a maximum likelihood estimation algorithm (hypomh) (Hirata and Matsu'ura, 1987). It is difficult to adequately deter- 


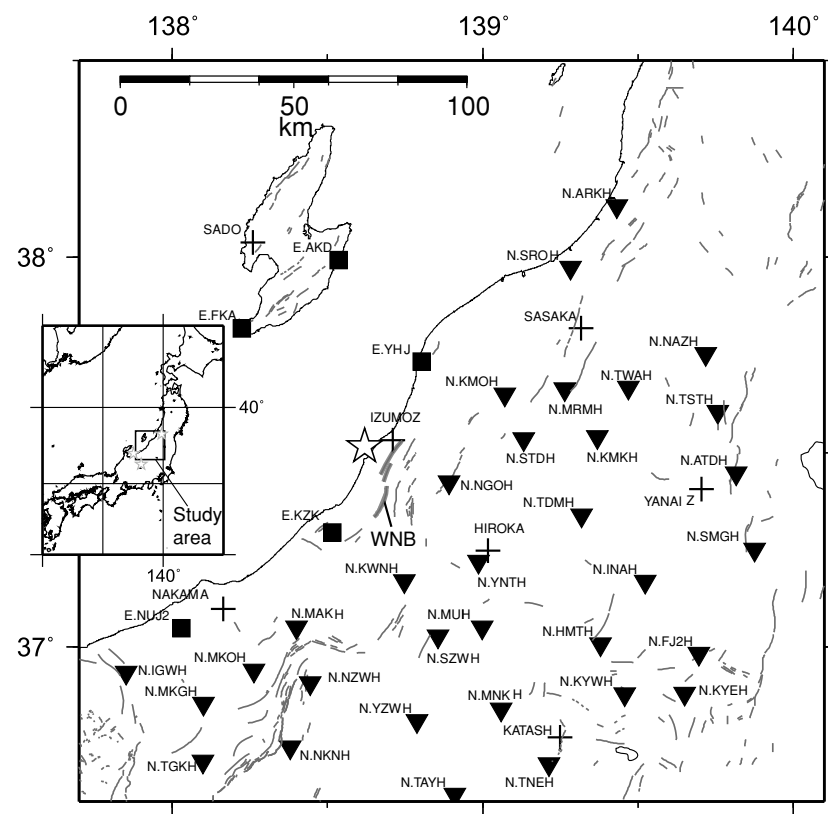

Fig. 1. Map showing the location of the stations (triangles: NIED stations, squares: ERI stations, crosses: JMA stations) used in this study. The star denotes the epicenter of the main shock to be relocated in this study. In the inset map, the study area is shown by a rectangle with respect to the greater parts of Japan Island. The stars in the inset map denote the epicenters of the intermediate-depth earthquakes that occurred in the depth range of $150-120-\mathrm{km}$, which are used to estimate the travel time residual at each station. The gray lines show the surface trace of the active fault (Research Group for Active Faults of Japan, 1991). WNB indicates the surface trace of the Western Nagaoka Basin active fault system.

mine the absolute hypocenter locations by employing only the one-dimensional velocity structure because of the thick marine sedimentary layers with a low velocity at depths of up to $5 \mathrm{~km}$ in the Niigata basin (e.g. Takeda et al., 2004). Thus, in addition to the one-dimensional velocity model, we employed station corrections for the $P$-and $S$-waves that were derived from the aftershock data of the $2004 \mathrm{Mid} \mathrm{Ni-}$ igata Prefecture Earthquake using a joint hypocenter determination method (Kissling et al., 1994) estimated by Shibutani et al. (2005). These station corrections were coincident with the average travel time residual at each station for the three intermediate-depth earthquakes that occurred in the $150-250 \mathrm{~km}$ depth range around the study area (Fig. 1). Since the ray paths to each station from these intermediateearthquakes and the 2004 Mid Niigata Prefecture Earthquake area are different except at the near surface area, this result suggests that the station corrections reflect the threedimensional velocity structure variations at the near surface area. As a result of employing the one-dimensional structure and station corrections in the hypomh algorithm, the hypocenters shifted upward by approximately $10 \mathrm{~km}$ from the corresponding hypocenters determined by the Hi-net routine analysis. The root mean square (RMS) of the travel time residuals decreased from $603 \mathrm{~ms}$ to $399 \mathrm{~ms}$.

The source region is barely beyond the station network, as shown in Fig. 1. In order to examine the effect of station coverage on the absolute earthquake location, we carried out a numerical test using the station distribution shown in Fig. 1. We assumed two hypocenters in the source region, as (a)

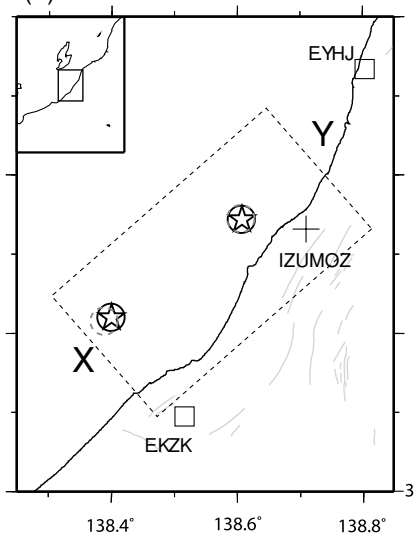

(b)

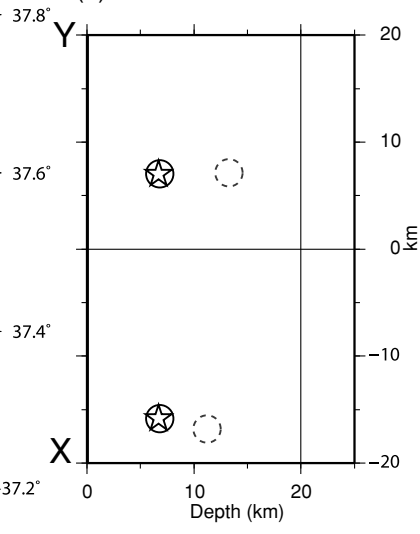

Fig. 2. The assumed and calculated hypocenter distribution for the numerical test. The stars indicate the assumed hypocenters. The black and broken circles denote the hypocenters calculated using the synthetic data that delayed the arrival time at the IZUMOZ, as described in the text. (a) Hypocentral distribution and (b) depth section along the $\mathrm{X}-\mathrm{Y}$ direction.

indicated by the stars in Fig. 2. We calculated the theoretical arrival time at each station using the velocity structure estimated by Shibutani et al. (2005). Then, the random noises within $\pm 30 \mathrm{~ms}$ and $\pm 50 \mathrm{~ms}$ were added for the $P$ - and $S$-arrival times, respectively. We located the hypocenters based on these synthetic data using the hypomh algorithm and the same velocity structure. As a result, we were able to determine the locations and origin times within $\pm 0.2 \mathrm{~km}$ and $5 \mathrm{~ms}$, respectively, from the assumed hypocenters. This result suggests that we can constrain the absolute earthquake locations and origin times from this station coverage if we apply the appropriate velocity structure. In order to examine the effect of the heterogeneity of the velocity structure, we purposely delayed the arrival times of synthetic data at the IZUMOZ station for $0.8 \mathrm{~s}$ and $1.6 \mathrm{~s}$ for the $P$ and $S$-arrival times, respectively. From the station correction estimated by Shibutani et al. (2005) and the travel time residual for intermediate-depth earthquakes, it is found that this station has a large positive travel time residual. From these synthetic data, the depths of the hypocenters were determined to be $2-6 \mathrm{~km}$ deeper than those of the assumed hypocenters, as indicated by the broken circles in Fig. 2. An appropriate station correction compensates for such a travel time residual caused by the heterogeneous velocity structure at the near surface area. The decreasing RMS of travel time residuals on the application of the station correction mentioned above suggests that the effect of the heterogeneous velocity structure at the near surface area was appropriately corrected.

\subsection{Hypocenter relocation}

The hypoDD algorithm was applied to the doubledifference data using the initial hypocenters noted above. The differential arrival times for the manually picked $P$ and $S$-wave were 138,955 and 141,606 pairs, respectively. We also used the differential arrival times obtained by the waveform cross-correlation analysis. The correlation measurements were conducted using a velocity waveform with a time window of $1.25 \mathrm{~s}$ applied to a $3-$ to $20-\mathrm{Hz}$ bandpass filter, including the manually picked $P$ - or $S$-wave arrival 
times. We used only the double-difference data with a normalized cross-correlation coefficient greater than or equal to 0.85 . After applying this threshold, we obtained a data set of accurate differential arrival times that contained 8,533 $P$-wave observations and $12,891 S$-wave observations. During the iterations of the hypoDD algorithm, the events were deleted if they lost connection with the other events or if they were located above the ground surface. A total of $48 \%$ of the 1,216 events were successfully relocated, including both the manually picked and cross-correlation data. After the hypoDD procedure, the RMS of the double-difference time residual decreased from $294 \mathrm{~ms}$ to $186 \mathrm{~ms}$ and from $184 \mathrm{~ms}$ to $7 \mathrm{~ms}$ for the manually and cross-correlation data, respectively.

In order to assess the uncertainty of the hypocenter location, we applied the bootstrap resampling method (Shearer, 1997) to all relocated events. The synthetic data set was calculated by assigning the predicted travel times at the final location with the randomly resampled residuals. We then relocated all of the events using the synthetic data set to determine a shift in the location from the final hypocenter. This process was repeated 200 times. The relative location error of each hypocenter is defined as the standard deviation $(2 \sigma)$ for the location shifts from the final hypocenters. The relative location errors were less than $0.43 \mathrm{~km}, 0.45 \mathrm{~km}$, and $1.4 \mathrm{~km}$ in the EW, NS, and vertical directions, respectively, for $90 \%$ of all the relocated events. On the other hand, the relative location errors were less than $0.055 \mathrm{~km}, 0.056 \mathrm{~km}$, and $0.24 \mathrm{~km}$ in the EW, NS, and vertical directions, respectively, for $90 \%$ of the events that were relocated using both the manually picked and cross-correlation data.

\section{Results}

Figure 3 shows the distribution of the selected events with relative errors of less than $1.5 \mathrm{~km}$ in the EW, NS, and vertical directions. A total of $91 \%$ of the relocated events were selected. The hypocenters relocated by both the manually picked and cross-correlation data and only the manually picked data are denoted by the solid and open circles, respectively. The corresponding moment tensor solutions estimated from the NIED F-net broadband waveform data (Matsumoto et al., 2007) are also shown in Fig. 3. The aftershocks extended for approximately $25 \mathrm{~km}$ in the direction of $\mathrm{N} 38^{\circ} \mathrm{E}-\mathrm{S} 38^{\circ} \mathrm{W}$. The trend of aftershock epicenter distributions in the map view is almost consistent with the strikes of the nodal planes of the moment tensor solutions. The aftershock depth distribution along the $\mathrm{X}-\mathrm{Y}$ cross section in Fig. 3 is deeper (down to approximately $20 \mathrm{~km}$ ) at the northeast part, while it is shallower at the southwest part. The largest aftershock occurred at the deepest point. The upper limit of the aftershock depth distributions is approximately $3 \mathrm{~km}$. We can observe the sparse aftershock distributions along the $\mathrm{X}-\mathrm{Y}$ cross section (surrounded by the broken ellipsoids). The ordinary seismic activity before the main shock, illustrated by the light red color in Fig. 3, mainly distributes in the 15 - to $20-\mathrm{km}$ depth range around the lower limit of the aftershock depth distributions.

Figure 4 shows the cross-sectional view perpendicular to the $\mathrm{X}-\mathrm{Y}$ direction in Fig. 3. The aftershock distribution is predominantly southeastward dipping. The dip angles

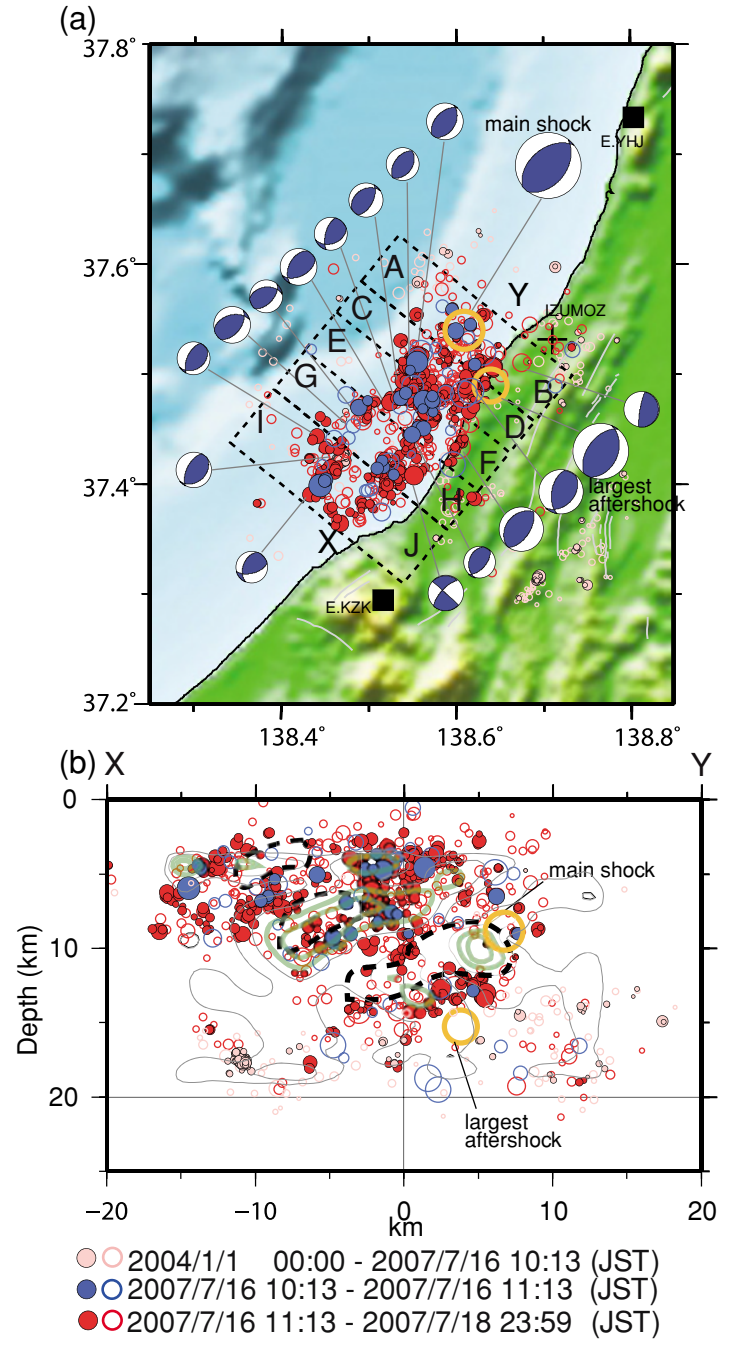

Fig. 3. (a) Map of the relocated earthquake hypocenters determined by the double-difference earthquake algorithm. (b) Depth section of the relocated earthquakes along the strike of the nodal planes for the main shock moment tensor (X-Y direction in Fig. 3(a)). The orange circles indicate the locations of the main shock and largest aftershock. The light red, blue, and red circles indicate the locations of the earthquakes that occurred in the period between midnight, January 1, 2004 (JST) and 10:13 AM, July 16, 2007 (JST), 10:13 AM, July 16, 2007 (JST) and 11:13 AM, July 16, 2007 (within an hour after the main shock) (JST), and 11:13 AM, July 16, 2007 (JST) and 11:59 PM, July 18, 2007 (JST), respectively. The events relocated by both the manually picked and cross-correlation data are indicated by solid circles, and those relocated by only the manually picked data are indicated by open circles. The corresponding moment tensor solutions (Matsumoto et al., 2007) are also shown. The contour lines along the $\mathrm{X}-\mathrm{Y}$ cross section indicate the slip distribution that was estimated by Aoi et al. (2008) assuming the southeastward dipping fault plane. The large slip areas exceeding a dislocation of $1.5 \mathrm{~m}$ are indicated by green transparent lines.

of these aftershock alignments are consistent with that of the nodal plane of the moment tensor solutions. Along the cross section of A-B and C-D in Fig. 4, the aftershocks are distributed in both the southeast and northwest dipping directions in the area above the $10-\mathrm{km}$ depth, as illustrated by the red, orange, and blue lines. Along the cross sections of $\mathrm{C}-\mathrm{D}$ and $\mathrm{E}-\mathrm{F}$ in Fig. 4, the aftershock distributions slope downward in the southeast direction with a dip of $50^{\circ}$, as illustrated by the orange lines. We can also observe the southeastward dipping aftershock alignment with a low dip 

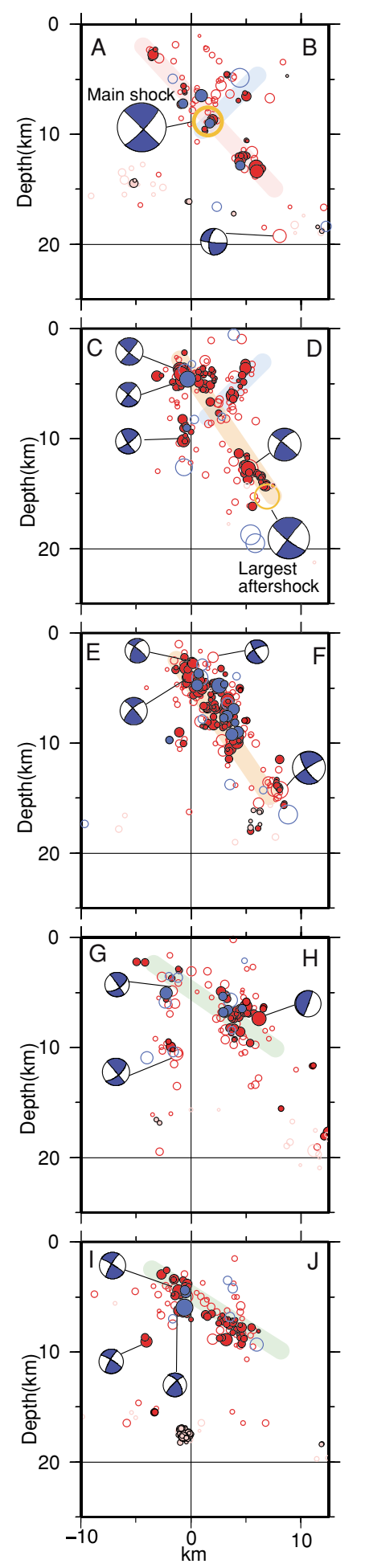

Fig. 4. Depth section of the relocated earthquakes. Each section corresponds to the rectangular area drawn in Fig. 3 (the perpendicular direction of the nodal plane of the main shock moment tensor solution). The corresponding moment tensor solutions are also shown. Red, blue, orange, and green lines indicate the aftershock alignments. The significance of the circles of each color is described in the caption of Fig. 3. The spacing of each section along the $\mathrm{X}-\mathrm{Y}$ direction in Fig. 3 was chosen to fit offsets in the aftershock distribution.

angle of $30^{\circ}$, as illustrated by the green line along the cross sections of G-H and I-J in Fig. 4.

Within an hour after the occurrence of the main shock, aftershocks occurred across the entire aftershock region, as indicated by the blue circles in Figs. 3 and 4. However, a small number of aftershocks occurred around the largest aftershock hypocenter (X-Y cross section in Fig. 3 or A-B, $\mathrm{C}-\mathrm{D}$, and E-F cross sections in Fig. 4). The aftershocks in this area were activated after the largest aftershock. These aftershocks are associated with the largest aftershock. In the northeast part of the aftershock area, aftershocks occurred within an hour after the main shock on both the southeastward and northwestward dipping aftershock alignments in the area above the $10-\mathrm{km}$ depth $(\mathrm{A}-\mathrm{B}$ and $\mathrm{C}-\mathrm{D}$ cross sections in Fig. 4).

\section{Discussion}

We have modeled the fault structure based on the relocated aftershocks, as shown in Fig. 5. We can identify four individual faults that are consistent with the aftershock distributions and moment tensor solutions. This fault model suggests that the main shock predominantly ruptured the southeastward dipping fault planes. The dip angle of the southeast dipping fault plane is significantly lower than that in the northern part. This result suggests that the main shock fault has segments between the northern and southern parts of the aftershock region. Around the hypocenter of the main shock, aftershocks occurred on both the fault planes within an hour after the main shock. The maximal aftershock in this area is $M 4.9$ (on the northwest dipping alignment at a 5-km depth along the A-B cross section in Fig. 4) whose fault size is smaller than the northwest dipping fault in our model. The conjugate fault planes dipping northwestward and southeastward may be nearly coincidentally ruptured during the main shock. The deep part of the Western Nagaoka Basin active fault system dipping westward (Fig. 1) may be connected with the northwestward dipping fault plane.

The sparse aftershock distributions along the $\mathrm{X}-\mathrm{Y}$ cross section (Fig. 3) are almost consistent with the large slip area during the main shock wherein a large slip exceeding a dislocation of $1.5 \mathrm{~m}$ was detected by an inversion of strong motion data (Aoi et al., 2008) whose fault geometry is agreement with the aftershock distribution. It is possible that the stress accumulated on the main shock fault was largely re-

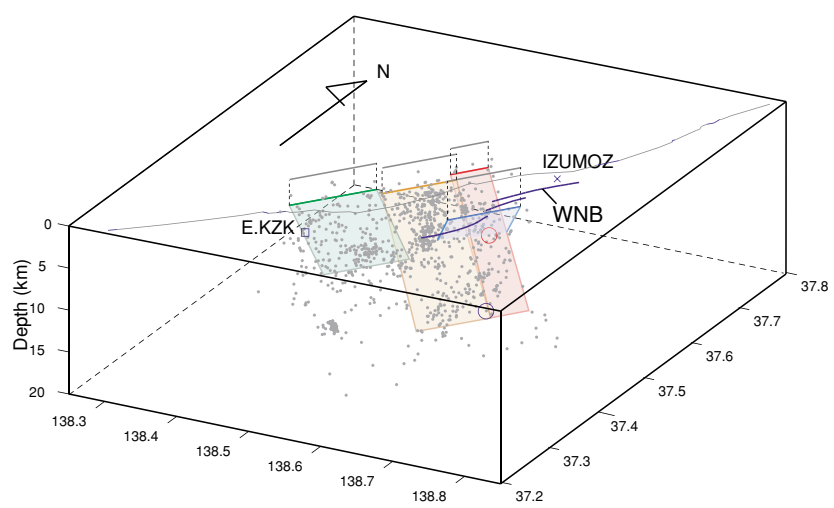

Fig. 5. Perspective view of the inferred fault plane orientation from the relocated aftershock distributions. Red and blue circles indicate the location of the main shock and the largest aftershock, respectively. Gray dots indicate the relocated hypocenters. Blue lines indicate the surface traces of the WNB. 
leased due to the large slip. The aftershock distributions occurring within an hour after the main shock suggest that the rupture during the main shock spread across the entire aftershock region, except in the area around the largest aftershock.

The hypocentral depth of the events relocated in our analysis is approximately $10 \mathrm{~km}$ shallower than that of the corresponding events determined by the Hi-net routine analysis. This result is consistent with the source model derived from the crustal deformation detected using synthetic aperture radar (SAR) interferometry (Ozawa, 2008) wherein the upper end of the slip area on the main shock fault model is at a depth of $2.5 \mathrm{~km}$. The optimal centroid depth of the moment tensor solutions (Matsumoto et al., 2007) is also consistent with the depth of our result. The average difference between the depths of corresponding events is $2.2 \mathrm{~km}$. These results support the validity of our analysis.

\section{Conclusions}

We obtained highly accurate hypocenters with the double-difference earthquake relocation algorithm using both the manually picked and cross-correlation data. From the relocated aftershock distribution, we successfully resolved the detailed fault structures that are consistent with the aftershock distributions and moment tensor solutions. From the fault model, we conclude that the main shock predominantly ruptured the southeastward dipping fault planes. Around the main shock hypocenter, the conjugate fault planes dipping northwestward and southeastward might be nearly coincidentally ruptured during the main shock.

Acknowledgments. We are grateful to F. Waldhauser for the hypoDD program code. We thank Dr. Takuo Shibutani for providing us with the one-dimensional velocity structure and station correction derived from the aftershock data of the 2004 Mid Niigata Earthquake. We also thank the Japan Meteorological Agency and Earthquake Research Institute of the University of Tokyo for allowing us to use the waveform data. We are grateful to Terry Webb, an anonymous reviewer, who greatly helped us to improve this manuscript, and Kiyoshi Yomogida for editing it. The majority of the figures were created using Generic Mapping Tools (GMT) (Wessel and Smith, 1995).

\section{References}

Aoi, S., H. Sekiguchi, N. Morikawa, and T. Kunugi, Source process of the 2007 Niigata-ken Chuetsu-oki earthquake derived from near-fault strong motion data, Earth Planets Space, 60, this issue, 1131-1135, 2008.

Hirata, N. and M. Matsu'ura, Maximum-likelihood estimation of hypocenter with origin time eliminated using nonlinear inversion technique, Phys. Earth Planet. Inter., 47, 50-61, 1987.

Japan Meteorological Agency, http://www.jishin.go.jp/main/chousa/07jul _chuetsu_oki, 2007.

Kissling, E., W. L. Ellsworth, D. Eberhart-Phillips, and U. Kradolfer, Initial reference models in local earthquake tomography, J. Geophys. Res., 99, 19635-19646, 1994.

Matsumoto, T., H. Matsubayashi, and T. Kazakami, F-net Moment Tensor Solution on The Niigataken Chuetsu-oki Earthquake in 2007, Seismol. Soc. Jpn. Programme. Abstr. Fall Meeting, 2007 (in Japanese).

Okamura, Y., S. Kuramoto, and M. Sato, Active structures and their relation to earthquakes along the eastern margin of the Japan Sea, Bull. Geol. Surv., 49, 1-18, 1998 (in Japanese with English abstract).

Ozawa, T., Coseismic deformatoin of the 2007 Chuetsu-oki earthquake derived from PALSAR/InSAR and its fault model, Earth Planets Space, 60, this issue, 1099-1104, 2008.

Research Group for Active Faults of Japan, Active Faults in Japan, revised edition, 437 pp., University of Tokyo Press, Tokyo, 1991 (in Japanese).

Sagiya, T., S. Miyazaki, and T. Tada, Continuous GPS array and presentday crustal deformation of Japan, Pure Appl. Geophys., 157, 23032322, 2000.

Shearer, P., Improving local earthquake locations using the L1 norm and waveform cross correlation: Application to the Whittier Narrows, California, aftershock sequence, J. Geophys. Res., 102, 8269-8283, 1997.

Shibutani, T., Y. Iio, S. Matsumoto, H. Katao, T. Matsushima, S. Ohmi, F. Takeuchi, K. Uehira, K. Nishigami, B. Enescu, I. Hirose, Y. Kano, Y. Kohno, M. Korenaga, Y. Mamada, M. Miyazawa, T. Ueno, H. Wada, and Y. Yukutake, Aftershock distribution of the 2004 Mid Niigata Prefecture Earthquake derived from a combined analysis of temporary online observations and permanent observations, Earth Planets Space, 57, 545-549, 2005.

Takeda, T., H. Sato, T. Iwasaki, N. Matsuta, S. Sakai, T. Iidaka, and A. Kato, Crustal structure in the northern Fossa Magna region, central Japan, from refraction/wide-angle reflection data, Earth Planets Space, 56, 1239-1299, 2004.

Townend, J. and M. D. Zoback, Stress, strain, and mountain building in central Japan, J. Geophys. Res., 111, doi:10.1029/2005JB003759, 2006. Waldhauser, F. and W. L. Ellsworth, A double-difference earthquake location algorithm: Method and application to the Northern Hayward fault, Bull. Seismol. Soc. Am., 90, 1352-1368, 2000.

Wessel, P. and W. H. F. Smith, New version of the generic mapping tools released, Eos Trans. AGU, 76, 329, 1995.

Y. Yukutake (e-mail: yukutake@onken.odawara.kanagawa.jp), T. Takeda, and K. Obara 